\title{
TREINAMENTO RESISTIDO REDUZ RISCOS CARDIOVASCULARES EM IDOSAS
}

\author{
RESISTED TRAINING REDUCES CARDIOVASCULAR RISK IN ELDERLY WOMEN
}

ENTRENAMIENTO RESISTIDO REDUCE EL RIESGO CARDIOVASCULAR EN MUJERES MAYORES

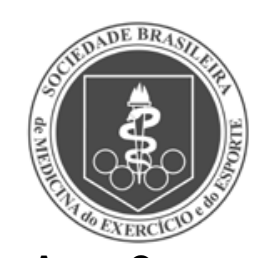

Artigo Original

Original Article

Artículo Original
Luís Ângelo Macêdo Santiago' (Fisioterapeuta)

Lídio Gonçalves Lima Neto² (Farmacêutico-Bioquímico)

Paulo Vitor Albuquerque Santana ${ }^{1}$ (Educador Físico)

Pauliana Conceição Mendes' (Educadora Física)

Washington Kleber Rodrigues Lima² (Farmacêutico-Bioquímico)

Francisco Navarro ${ }^{1}$

(Educador Físico)

1. Universidade Federal do Maranhão (UFMA) São Luís, MA, Brasil. 2. Universidade CEUMA, São Luís, MA, Brasil.

\section{Correspondência:}

Laboratório de Fisiologia e Prescrição do Exercício, Departamento de Educação Física, Universidade Federal do Maranhão, UFMA. Av. dos Portugueses, 1966, Bacanga. CEP: 65080-805, São Luís, MA, Brasil. angelo_santiago@ibest.com.br

\section{RESUMO}

Introdução: O envelhecimento humano aliado ao estilo de vida sedentário é marcado por alterações metabólicas com modificação na composição corporal, que repercutem diretamente na proteína C-reativa $(P C R)$, sendo este um importante marcador de risco de doenças cardiovasculares (DCV). O treinamento resistido (TR) é um método muito utilizado na prevenção de doenças associadas ao envelhecimento. Objetivo: Avaliar os efeitos de oito semanas de TR sobre a composição corporal, força muscular e PCR em um grupo de idosas. Método: Foi realizado um estudo experimental com 10 idosas (63 \pm 2 anos de idade). Para o ensaio de PCR, análises bioquímicas de hemograma e lipidograma completos foram coletadas amostras de sangue venoso periférico antes do exercício e 24 horas depois. Para medidas antropométricas calcularam-se índice de massa corporal (IMC), relação cintura/quadril (RCQ) e composição corporal. O TR foi realizado por Série Combinada - Bi-Set. Para a análise estatística, primeiramente foi realizado o teste de normalidade de Shapiro-Wilk $(p>0,05)$ para testes paramétricos. As variáveis do grupo foram apresentadas como média e desvio padrão. Para variáveis de PCR, antropométricas, composição corporal e perfil lipídico foram realizados o teste $t$ de Student, tanto anterior quanto posteriormente às oito semanas de treinamento. Para as amostras da evolução das cargas e médias do consumo alimentar foi realizado o teste One Way ANOVA e, quando necessário, o teste post hoc de Tukey. O nível de significância adotado foi de $p \leq 0,05$. Resultados: Houve redução estatisticamente significativa $(p=0,02)$ para as concentrações séricas de $P C R$, o que significa uma redução de $70,96 \%$, além de diminuir a massa gorda e aumentar a massa magra e a carga de treino após oito semanas. Conclusão: Oito semanas de TR reduziram as concentrações séricas de proteína C-reativa, assim como diminuíram a massa gorda e aumentaram o volume muscular, demonstrando ser uma estratégia eficiente para a diminuição dos fatores de riscos de doenças cardiovasculares.

Palavras-chave: exercício, tecido adiposo, testes hematológicos.

\section{ABSTRACT}

Introduction: Human aging combined with a sedentary lifestyle is marked by metabolic changes with change in body composition reflecting directly on the C-reactive protein (CRP), which is an important risk marker for cardiovascular disease (CVD). Resistance Training (RT) is a widely used method in the prevention of diseases associated with aging. Objective: To evaluate the effects of eight weeks of TR on body composition, muscle strength and CRP in a group of elderly women. Method: An experimental study was conducted with 10 elderly women ( $63 \pm 2$ years). For the CRP analysis, biochemical analysis, complete blood count and lipid profile samples of peripheral venous blood were collected before exercise and 24 hours later. For anthropometric measurements were calculated the body mass index (BMI), waist/hip ratio (WHR) and body composition. The TR was conducted by Combined Series - Bi-Set. Statistical analysis was first conducted with the Shapiro-Wilk normality test ( $p>0.05$ ) for parametric tests. Group variables were presented as mean and standard deviation. For CRP, anthropometric, body composition and lipid profile variables, the Student t test was performed, for both previous and later to eight weeks of training. For samples of the loads evolution and average food consumption was performed the One Way ANOVA test and, where necessary, the Tukey's post hoc test. The significance level was set at $p \leq 0.05$. Results: There was a statistically significant reduction $(p=0.02)$ for the serum concentrations of CRP, which means a decrease of $70.96 \%$, and reduction of the fat mass and increased lean body mass and the training load after eight weeks. Conclusion: Eight weeks of RT reduced serum concentrations of C-reactive protein, as well as decreased fat mass and increased muscle volume, proving to be an effective strategy in reducing the risk factors for cardiovascular disease.

Keywords: exercise, adipose tissue, hematologic tests.

\section{RESUMEN}

Introducción: El envejecimiento humano combinado con un estilo de vida sedentario está marcado por cambios metabólicos con el cambio en la composición corporal que afectan directamente a la proteína C-reactiva (PCR), que es un marcador importante de riesgo de enfermedad cardiovascular (ECV). El entrenamiento de resistencia (RT) es un método ampliamente utilizado en la prevención de las enfermedades asociadas con el envejecimiento. Objetivo: Evaluar los efectos de las ocho semanas de TR en la composición corporal, la fuerza muscular y la PCR en un grupo de personas de edad avanzada. Método: Un estudio experimental se llevó a cabo con 10 mujeres de edad avanzada 
(63 \pm 2 años). Para prueba PCR, el análisis bioquímico, hemograma completo y perfil lipídico completo se recogieron muestras de sangre venosa periférica antes del ejercicio y 24 horas después. Para las medidas antropométricas se calcularon el índice de masa corporal (IMC), indice cintura/cadera (ICC) y composición corporal. El TR fue realizado por la Serie Combinada - Bi-Set. El análisis estadístico se realizó por primera vez con la prueba de normalidad de Shapiro-Wilk $(p>0,05)$ para las pruebas paramétricas. Las variables de grupo se presentan como media y desviación estándar. La PCR, las variables antropométricas, la composición corporal y el perfil lipídico se realizaron con la prueba de la t de Student, tanto anterior cuanto posteriormente a las ocho semanas de entrenamiento. Para las muestras de cambios de carga y el consumo medio de alimentos se realizó la prueba One Way ANOVA y, cuando necesario, la prueba post hoc de Tukey. El nivel de significación se fijó en $p \leq 0,05$. Resultados: Hubo una reducción estadísticamente significativa $(p=0,02)$ para las concentraciones séricas de $P C R$, lo que significa un descenso del 70,96\%, y reducción la masa grasa y aumento de la masa corporal magra y la carga de entrenamiento después de ocho semanas. Conclusión: Ocho semanas de RT reducen las concentraciones séricas de proteína C-reactiva, así como de la masa grasa, aumentaron el volumen muscular, demostrando ser una estrategia eficaz para la reducción de los factores de riesgo de enfermedad cardiovascular.

Palabras clave: ejercicio, tejido adiposo, pruebas hematológicas.

\section{INTRODUÇÃO}

O aumento na expectativa de vida tem sido estudado por vários anos e por diversas áreas, tempos atrás era privilégios de poucos chegarem à velhice, atualmente é considerado um feito comum a todos'.

O envelhecimento é um processo natural e marcado por importantes alterações, tanto biológicas, quanto fisiológicas, onde variam de indivíduo para indivíduo e dependem de vários fatores, dentre eles o estilo de vida ${ }^{2}$. Estudos apontam esse processo como um desafio mundial, responsável pelo aumento na demanda de cuidados, especialmente, por profissionais da área da saúde, uma vez que esse estilo de vida repercute diretamente em sua composição corporal, principalmente aumento do tecido adiposo com conseguinte aumento nas concentrações séricas de marcadores inflamatórios como é o caso da proteína C-Reativa (PCR) considerada a principal proteína de fase aguda e indicador de riscos cardiovasculares acarretando risco a saúde do idoso e aumento de morbidade e mortalidade nessa população 2,3.

Por outro lado, o treinamento resistido (TR) é um método muito utilizado na prevenção de doenças associadas ao desenvolvimento de co-morbidade e mortalidade em idosos, assim como melhora no desempenho físico através da força muscular da população em geral, desta forma, é necessário que devam ser aplicadas sobrecargas progressivas de esforço durante as sessões de treino, a fim de provocar distúrbios da homeostasia celular e a consequente uma resposta adaptativa a esse estresse $e^{4,5}$.

O principio da sobrecarga é um dos princípios do TR necessários para o aumento do desempenho físico. Pressupõe-se que devem ser aplicadas de forma progressiva de esforço durante as sessões de treino, objetivando provocar um distúrbio da homeostasia celular e como resposta uma adaptação a esse estresse. Essas adaptações acontecerão tanto a nível muscular, quanto neural e molecular, onde essa modalidade de treinamento provocará microtraumas, onde os mesmos são dependentes da intensidade do esforço e incluem ruptura da matriz extracelular, lamina basal e do sarcolema ${ }^{6}$. O mecanismo de reparo do dano e altamente sincronizado e didaticamente pode ser dividido basicamente em três fases: uma fase degenerativa seguida de uma fase regenerativa, e uma terceira fase de remodelamento do tecido danificado ${ }^{7}$. Constitui uma cascata de eventos, no qual as células inflamatórias promovem tanto dano quanto regeneração. Isso é feito através da ação combinada de vários, fatores como, hormônios de crescimento e citocinas, que mantem um equilíbrio entre atividades pró-inflamatória e anti-inflamatória ${ }^{8,9}$.
Desta forma, o envelhecimento humano saudável é um grande desafio mundial, pois, para que isso aconteça, mudanças de estilo de vida são necessários, principalmente com relação ao sedentarismo. Observar o comportamento dos marcadores inflamatórios frente ao TR crônico em idosas pode ser uma boa ferramenta para vários profissionais de saúde, e principalmente a população em geral com relação a concepção dos efeitos benéficos que o exercício físico pode trazer nessa fase senil. Perante os pressupostos apresentados, o proposito central deste estudo foi analisar, em um grupo de idosas, os efeitos de oito semanas de TR em marcador inflamatório de PCR, assim como, na composição corporal e força muscular, de modo a proporcionar uma melhor compreensão desses eventos.

\section{MÉTODOS}

A pesquisa foi caracterizada do tipo experimental, onde inicialmente, 11 idosas participaram da pesquisa, sendo que uma não completou a pesquisa por se enquadrar em um dos critérios de exclusão, finalizando com $(n=10)(63 \pm 2,18)$. O estudo experimental foi aprovado na Comissão Nacional de Ética em Pesquisa (CONEP) para projetos de pesquisa experimental envolvendo seres humanos, sob parecer de No do CAEE: 10863313.2.1001.5084 parecer de № 372.453/2013. Inicialmente, as participantes foram contatadas pela Universidade da Terceira Idade - UNITI, após contato prévio as mesmas assinaram o Termo de Consentimento Livre e Esclarecido (TCLE). Para critérios de exclusão, participantes com hipertensão arterial e diabetes mellitus descompensados em anamnese dirigida, participantes com alterações de parâmetros em exames bioquímicos, participantes que obtiveram frequência menor que $85 \%$ das sessões ao longo das oito semanas do programa de treino.

\section{Protocolo do treinamento resistido}

O protocolo do TR foi baseado em uma analise crítica seguindo as bases de dados dos seguintes autores ${ }^{10,13}$, sendo assim, os treinos foram realizados em aparelhos de musculação por um período de tempo total de oito semanas. O tipo de treino foi por série combinada do tipo BI-SET que consiste em realizar dois exercícios sem intervalo de tempo para grupos musculares distintos, membros inferiores (MMII) e membros superiores (MMSS) e após sua realização, segue-se um intervalo para que seja feita a segunda passagem, após repetir o intervalo, inicia-se a terceira passagem.

Frequência semanal: três vezes por semana e incluiu oito exercícios divididos em membros superiores e inferiores: leg press sentado (aparelho de sobrecarga mecânica para as pernas), supino sentado, extensão de joelhos, 
pulley costas, flexão de joelhos deitado, flexão de cotovelos na polia baixa, flexão plantar no leg press sentado, extensão de cotovelos na polia.

Número de repetições: Foi realizada através de zona de repetição priorizando hipertrofia muscular, (8-12 Repetições).

Incremento da intensidade (carga-kg): as participantes executaram seu programa de TR dentro de uma zona de repetição máxima compreendida entre 8 a 12 repetições, desta forma, toda vez que as participantes ultrapassavam os limites desta zona, novo incremento de carga acontecia para que mantivesse novamente dentro da zona estabelecida.

Intervalo de tempo e duração das sessões: foi estabelecido o descanso de um minuto entre os segmentos trabalhados e a duração em média de 50 minutos por sessão.

Velocidade realizada na execução dos exercícios: foi respeitada a velocidade de duração de três segundos para cada movimento, sendo 1,5 segundos para a fase concêntrica e 1,5 segundos para a fase excêntrica, controlado por comandos visuais e verbais para padronização das angulações de movimento ${ }^{11}$.

Inicialmente, as participantes realizaram uma semana de familiarização ao TR, composto por duas séries de 15 repetições submáximas com o objetivo de conhecerem os exercícios e suas respectivas execuções e promover adaptações neuromusculares evitando assim o surgimento excessivo de dor muscular de início tardio (DMIT) para em seguida darem início ao TR. Antes e após todas as sessões de treino, as participantes aguardavam em repouso na sala por 5 min para medida da pressão arterial para controle dos padrões vitais. 0 programa de TR foi orientado e supervisionado por um Fisioterapeuta e dois Profissionais de Educação Física.

Para controle dos parâmetros antropométricos e de índice de massa corporal (IMC), foram mensuradas as seguintes variáveis: A massa corporal, estatura e cálculo do IMC foram realizadas através das medidos obtidas em balança digital (Welmy ${ }^{\circledR}$-W300, Brasil), com capacidade máxima de $300 \mathrm{~kg}$. Em seguida foram realizadas aferições de circunferência de cintura e quadril em fita métrica da marca (Waist Fit ${ }^{\circledR}$, Brasil) com a finalidade de obtermos dados de relação cintura/quadril (RCQ) que ambos permitem caracterizar o grau de obesidade.

Para a composição corporal, todas as participantes, antes das aferições, foram orientadas a não se alimentarem duas horas antes do teste, não ingerir bebida alcoólica e não realizar exercício físico 24 horas que antecederam o teste, controlar a ingestão de liquido e urinarem 30 min antes da avaliação. Em seguida, as participantes foram solicitadas a deitarem na maca para fixação dos eletrodos nos pontos pré- determinados e higienizados com álcool líquido a 70\%. Os eletrodos emissores foram posicionados nos seguintes locais: superfície dorsal da mão direita próximo à articulação metacarpofalangeana, região distal do arco transverso da superfície superior do pé direito e os eletrodos detectores foram posicionados na proeminência posterior da articulação do rádio - ulnar distal do punho direito e o outro entre o maléolo medial e lateral do tornozelo direito. Esse procedimento foi realizado por meio de bioimpedância elétrica tetrapolar (Maltron BF-906 Body Fat Analyser ${ }^{\circledR}$, Inglaterra).

Embora o tecido adiposo contribua para o aumento nas concentrações séricas de $\mathrm{PCR}^{14}$ foi necessário controlar e comprovar a regularidade dos hábitos alimentares através do controle do consumo alimentar semanal de todas as participantes. Para isso, todas foram orientadas por um Nutricionista, previamente treinado, a responderem um Questionário de Recordatório Alimentar de 24 horas (R24), três vezes por semana que consistiu em um checklist do número de alimentos e mensurou-se as quilocalorias (Kcal) diárias de cada participante por um período de tempo de oito semanas. A partir desses dados foram realizadas as medias \pm desvio padrão das oito semanas compreendidas ao TR.

\section{Coletas sanguíneas e análises bioquímicas}

As coletas de sangue foram realizadas por um flebotomista devidamente treinado, seguindo as normas de biossegurança preconizadas pela NR32, e aconteceram em dois momentos: pré (antecedente ao TR) e pós (24 horas após a última sessão de TR). As idosas foram orientadas a comparecerem ao local no período da manhã e em jejum máximo de 12 horas. As amostras sanguíneas foram coletadas a vácuo com um volume de aproximadamente $9 \mathrm{ml}$, distribuídos em um tubo EDTA (Vacuette) de $4 \mathrm{ml}$ e outro tubo seco contendo gel separador de coágulo (Vacuette) de $5 \mathrm{ml}$. Foram realizadas as seguintes medidas: a) a unidade contendo conservante EDTA foi para quantificação dos níveis séricos de hemograma completo (hemoglobina; leucócitos; basófilos; eosinófilos; linfócitos; monócitos; neutrófilos e plaquetas); b) as unidades do tubo seco contendo o gel separador de coágulo foram distribuídas para as análises bioquímicas do perfil lipídico (colesterol TOTAL, triglicérides, LDL e HDL-Colesterol) e Proteína C-Reativa. Após a coleta da amostra sanguínea, os tubos foram etiquetados e transportados em caixas térmicas hermeticamente fechadas e lacradas, sendo enviadas para o Laboratório de Análise Clínica para serem analisadas.

\section{Análise estatística}

Para análise estatística inicialmente foi realizado o teste de normalidade de Shapiro-Wilk apresentando um $(p>0,05)$ comprovando a utilização de testes paramétricos. As variáveis do grupo foram apresentadas como média e desvio padrão. Para variáveis de PCR, antropométricas, composição corporal e perfil lipídico foram realizados pelo teste $t$ Student pareado para os momentos pré e pós oito semanas de treinamento. Para as amostras da evolução das cargas e controle do consumo alimentar semanal do grupo foi realizado o Teste One Way ANOVA e quando necessário, teste post hoc de Tukey. O nível de significância adotado foi de $(p \leq 0,05)$.

\section{RESULTADOS}

A amostra foi composta por 10 participantes com idade média de $63 \pm 2,18$ e estatura de 1,54 $\pm 0,01$. O grupo se manteve, antes do TR, dentro dos parâmetros de caracterização de sobrepeso com IMC de 28,74 $\pm 2,64 \mathrm{Kg} / \mathrm{m}^{2}$, assim como a RCQ de 0,83 $\pm 0,06 \mathrm{~cm}$. Ao compararmos os momentos pré e pós oito semanas de TR foi observada diferença estatisticamente significativa entre os momentos para as variáveis, massa corporal $(p=0,04)$; massa magra $(p=0,01)$; percentual de massa magra $(p=0,03)$; percentual de gordura $(p=0,03)$; $I M C(p=0,02)$. A caracterização da amostra final e momento pré e pós TR pode ser observada na tabela 1.

Para evolução da carga de treinamento nos momentos compreendidos entre a 1a , $4^{a}$ e $8^{a}$ semanas de treinos, houve uma progressão em suas cargas e em seus respectivos exercícios com diferença significativa entre as semanas ( $p=0,0001)$, (tabela 2).

Para obtermos o padrão de consumo alimentar no grupo foi aplicado o Questionário R24. Para os valores obtidos foi realizado o teste ANOVA para amostras dependentes (pareadas) entre os momentos da 1a $4^{a}$ e $8^{a}$ semanas. Não foram observados diferenças estatisticamente significantes $(p=0,1)$ no consumo calórico na $1^{a}, 4^{a}$

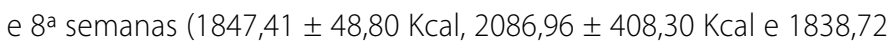
$\pm 611,38 \mathrm{Kcal}$, respectivamente).

Para os dados da concentração sérica de PCR, houve diminuição estatisticamente significativa ao comparar o momento pré 1,86 \pm 0,49 mg/L com o momento Pós 1,32 $\pm 0,32 \mathrm{mg} / \mathrm{L}(\mathrm{p}=0,02)$, o que representa uma diminuição de $70,96 \%$ na concentração sérica de PCR apresentada na figura 1. 
Tabela 1. Características da Amostra e comparação entre os momentos pós e pré

\begin{tabular}{c|c|c}
\hline Variáveis & \multicolumn{2}{|c}{$\mathbf{n}=10$} \\
\hline Idade & \multicolumn{2}{|c}{$63 \pm 2,18$} \\
\hline Estatura & \multicolumn{2}{|c}{$1,54 \pm 0,01$} \\
\hline & Pré & Pós \\
\hline Massa corporal $(\mathrm{kg})$ & $68,08 \pm 6,85$ & $69,48 \pm 8,09^{*}$ \\
\hline Massa gorda $(\mathrm{kg})$ & $27,13 \pm 4,39$ & $26,71 \pm 4,95$ \\
\hline Massa magra $(\mathrm{kg})$ & $40.95 \pm 3,66$ & $42,77 \pm 4,18^{*}$ \\
\hline Percentual de massa magra (\%) & $60,45 \pm 2,36$ & $61,56 \pm 1,28^{*}$ \\
\hline Percentual de gordura (\%) & $39,55 \pm 3,14$ & $38,44 \pm 3,18^{*}$ \\
\hline IMC $\left(\mathrm{kg} / \mathrm{m}^{2}\right)$ & $28,74 \pm 2,64$ & $29,09 \pm 3,09^{*}$ \\
\hline RCQ $(\mathrm{cm})$ & $0,83 \pm 0,06$ & $0,82 \pm 0,06$ \\
\hline Colesterol total $(\mathrm{mg} / \mathrm{dl})$ & $191,00 \pm 33,26$ & $184,40 \pm 36,81$ \\
\hline HDL $(\mathrm{mg} / \mathrm{dl})$ & $48,60 \pm 9,62$ & $50,10 \pm 14,27$ \\
\hline LDL $(\mathrm{mg} / \mathrm{dl})$ & $121,70 \pm 33,54$ & $113,80 \pm 37,37$ \\
\hline Triglicerídeos $(\mathrm{mg} / \mathrm{dl})$ & $103,80 \pm 39,94$ & $101,80 \pm 39,95$ \\
\hline
\end{tabular}

Os dados são apresentados como média \pm desvio padrão. Teste T Student para amostras pareadas.* Diferença estatisticamente significativa $(p<0,05)$ para as variáveis de massa corporal $(p=0,04)$, massa magra $(p=0,01)$, percentual de massa magra $(P=0,03)$ percentual de gordura $(P=0,03)$, IMC $(P=0,01)$. IMC Índice de Massa $C o r-$

Tabela 2. Evolução da carga de treino na 1a $4^{\mathrm{a}}$ e $8^{\mathrm{a}}$ semanas de treinamento.

\begin{tabular}{c|c|c|c}
\hline Exercícios & 1a Semana & 4a Semana & 8 $^{\text {a Semana }}$ \\
\hline Leg press 45 $(\mathrm{kg})$ & $18,93 \pm 7,82$ & $36,50 \pm 11,03^{*}$ & $46,83 \pm 14,47^{*} \dagger$ \\
\hline Rosca bíceps $(\mathrm{kg})$ & $8,83 \pm 4,61$ & $14,93 \pm 2,78^{*}$ & $18,76 \pm 3,17^{*} \dagger$ \\
\hline Leg extensão $(\mathrm{kg})$ & $12,09 \pm 4,78$ & $19,86 \pm 6,10^{*}$ & $27,64 \pm 5,65^{*} \dagger$ \\
\hline Supino sentado $(\mathrm{kg})$ & $8,06 \pm 3,58$ & $13,74 \pm 4,39^{*}$ & $15,52 \pm 5,21^{*} \dagger$ \\
\hline Mesa flexora $(\mathrm{kg})$ & $9,37 \pm 3,14$ & $15,55 \pm 2,73^{*}$ & $18,56 \pm 3,55^{*} \dagger$ \\
\hline Pulley frontal inverso $(\mathrm{kg})$ & $14,72 \pm 4,13$ & $22,82 \pm 4,24^{*}$ & $26,93 \pm 2,88^{*} \dagger$ \\
\hline Panturrilha leg sentado $(\mathrm{kg})$ & $22,76 \pm 6,30$ & $34,13 \pm 10,51^{*}$ & $48,66 \pm 10,80^{*} \dagger$ \\
\hline Tríceps pulley $(\mathrm{Kg})$ & $12,20 \pm 4,28$ & $17,36 \pm 4,00^{*}$ & $20,99 \pm 3,90^{*} \dagger$ \\
\hline
\end{tabular}

Os dados são apresentados como média \pm desvio padrăo. Teste One Way-ANOVA seguido do teste post hoc de Tukey. * Diferença estatisticamente significativa $(p=0,0001)$ comparado a $1^{\text {a }}$ semana. † Diferença estatisticamente significativa ( $p=0,0001)$ comparado a 4 a semana.

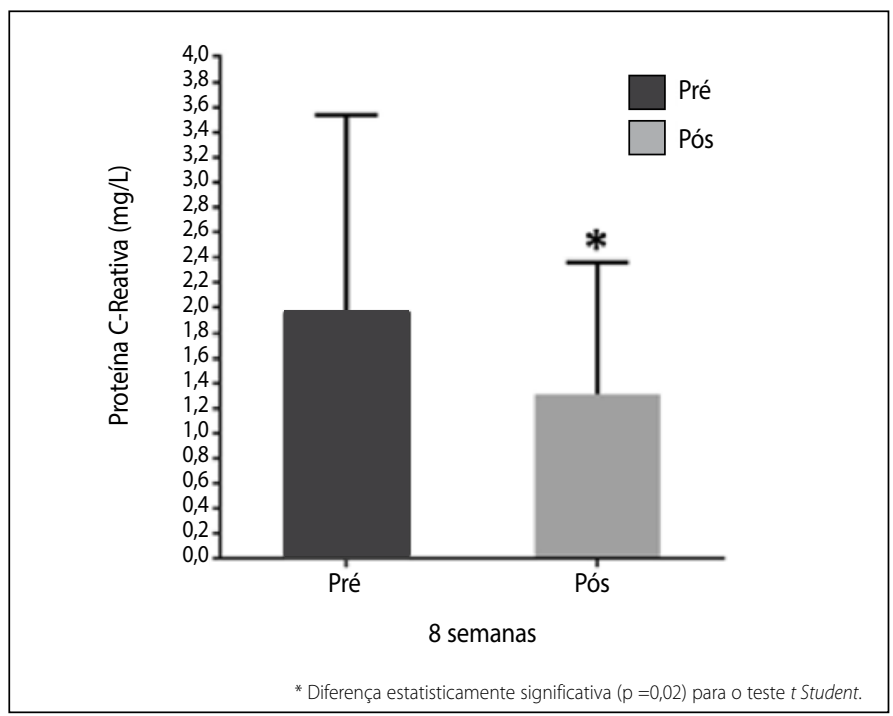

Figura 1. Concentrações séricas de Proteína C-Reativa nos momentos pré e pós treinamento.

\section{DISCUSSÃO}

No presente estudo, o TR reduziu as concentrações séricas de PCR após oito semanas de treinamento. Além disso, observou-se diminuição da massa gorda, RCQ e aumento da massa magra e da carga de treinamento.

O envelhecimento humano é um processo caracterizado por mudanças tanto biológicas quanto fisiológicas com repercussão na alteração da composição corporal dando surgimento a inflamação crônica, indicada pelo aumento de marcadores inflamatórios que são associados ao desenvolvimento de doenças cardiovasculares, aumento da co-morbidade e mortalidade em idosos ${ }^{15,16}$.
O exercício físico realizado de forma regular oferece proteção contra algumas causas de mortalidade, principalmente contra doenças cardiovasculares e diabetes mellitus tipo $2^{14,17,18}$. O tecido adiposo contribui para o aumento nas concentrações de PCR, o que repercuti em aumento de suas concentrações séricas ${ }^{14,17,19}$. A possível explicação para a diminuição da PCR após o TR pode ser por uma série de fatores, entre eles, o exercício físico induz redução da massa gorda pela mobilização dos lipídios e estimulação da lipólise que é regulada pela lipase e ativada pela estimulação beta-oxidativa, desta forma aumentando a captação e oxidação de ácidos graxos pelo músculo esquelético, servindo de substrato energético pelo mecanismo do ciclo glicose-acido graxo refletindo diretamente na diminuição do tecido adiposo e, por conseguinte redução nas concentrações séricas de marcador inflamatório (PCR), sendo este um evento benéfico, pois tem uma ação protetora contra doenças cardiovasculares ${ }^{19-21}$.

Desta forma, estudos similares corroboram com os achados do presente estudo, como o de Willis et al. ${ }^{6}$ que avaliaram os efeitos do treinamento aeróbio, treinamento resistido e treinamento concorrente por um período de oito meses na composição corporal em adultos com sobrepeso e obesos e mostrou que o treinamento aeróbio e treinamento concorrente tendenciaram uma redução da massa gorda. Outro estudo semelhante foi realizado por $\mathrm{HO}$ et al. ${ }^{22}$, onde observaram os efeitos em três modalidades de treinamento (treinamento aeróbio, treinamento resistido e treinamento concorrente) em participantes com idade entre 40 e 66 anos, acompanhados por 12 semanas e observaram diminuição da massa gorda e aumento massa magra. Lee et al. ${ }^{23}$ acompanharam os efeitos em oito semanas em dois tipos de treinamento (treinamento aeróbio e treinamento concorrente) em idosas na composição corporal e marcadores inflamatórios, como o caso da PCR, observaram redução da massa gorda e aumento da massa magra especialmente no treinamento aeróbio. Já para os marcadores inflamatórios o treinamento concorrente diminuiu as concentrações séricas de PCR, IL-6 e TNF-a em comparação ao treinamento aeróbio.

Observou-se também o aumento da força muscular, evidenciado com o aumento do volume muscular e aumento progressivo da carga de treinamento ao longo das oito semanas, esse episódio, segundo Prestes et al. ${ }^{24}$ é um ajuste do organismo à sobrecarga de treinamento, ocorrendo alterações fisiológicas (fatores neurais) e estruturais (fatores musculares), tendo como consequência, o aumento da força muscular. O aumento do volume e força muscular também pode influenciar diretamente na diminuição das concentrações séricas de marcador inflamatório (PCR), pois essas variáveis tem forte relação entre si ${ }^{17}$. Mavros et al. ${ }^{25}$ corroboram com os achados, onde estudaram os efeitos de 12 meses de TR sobre a PCR em idosos e associou suas respectivas reduções com as mudanças na composição corporal. Os autores concluíram que TR diminuiu as concentrações séricas de PCR, assim como associaram com o aumento da massa muscular esquelética $(p=0,01)$. No estudo de Lera et al. ${ }^{26}$ observaram a importância da frequência de 16 semanas de TR na composição corporal, glicose sanguínea e PCR em idosas menopausadas, sedentárias e com sobrepeso e os resultados indicaram que o TR aumentou a força e massa muscular, além de impedir o aumento da PCR.

Baseado nos estudos previamente apresentados, podemos especular que o treinamento sistematizado e progressivo de um programa de TR alterou a composição corporal com redução da massa gorda e aumento do volume e força muscular, com conseguinte diminuição da PCR. Esse treinamento é desenvolvido através de metas de treinamento adequadas e específicas e entre vários protocolos utilizados, a série combinada - Bi-Set mostra uma proposta eficiente de programa 
de TR individualizado e bem estruturado para alterar as variáveis estudadas e que segue as recomendações de prescrição do treinamento resistido para idosos.

\section{CONCLUSÃO}

Oito semanas de treinamento resistido reduziu as concentrações séricas de Proteína C-Reativa assim como diminuição da massa gorda, aumento do volume e força muscular, sendo uma eficiente estratégia na diminuição dos fatores de riscos para as doenças cardiovasculares.

\section{AGRADECIMENTOS}

Projeto financiado pela Universidade Federal do Maranhão-UFMA e Fundação de Amparo à Pesquisa do Estado do Maranhão (FAPEMA-BM-01486/13). Luís Ângelo Macêdo Santiago é bolsista de produtividade da CAPES.

Todos os autores declararam não haver qualquer potencial conflito de interesses referente a este artigo.

\section{REFERÊNCIAS}

1. Caldas CP. Aging with dependence: family needs and responsibilities. Cad Saude Publica. 2003;19(3):773-81.

2. Pappaléo NM. Gerontologia: a velhice e envelhecimento em uma visão globalizada, São Paulo: Atheneu; 1996.

3. Frühbeck G, Gómez-Ambrosi J, Muruzábal FJ, Burrell MA. The adipocyte: a model for integration of endocrine and metabolic signaling in energy metabolism regulation. Am J Physiol Endocrinol Metab. 2001;280(6):E827-47.

4. Amaral PN, Pomatti DM, Fortes VLF. Atividades físicas no envelhecimento humano: uma leitura sensível criativa. RBCEH. 2007:4(1):18-27.

5. Toigo $\mathrm{M}$, Boutellier U. New fundamental resistance exercise determinants o molecular and cellular muscle adaptations. Eur J Appl Physiol. 2006;97(6):643-63.

6. Willis $\mathrm{H}$, Cris AS, Lori AB, Shields AT, Lucy WP, Connie WB, et al. Effects of aerobic and/or resistance training on body mass and fat mass in overweight or obese adults. J Appl Physiol (1985). 2012;113(12):1831-7

7. Barry BK, Carson RG. The consequences of resistance training for movement control in older adults. J Gerontol A Biol Sci Med Sci. 2004;59(7):730-54.

8. Smith LL. Tissue trauma: the underlying cause of overtraining syndrome? J Strength Cond Res. 2004;18(1):185-93

9. Gleeson M. Immune function in sport and exercise. J Appl Physiol (1985). 2007:103(2):693-9.

10. Tidball JG. Inflammatory processes in muscle injury and repair. Am J Physiol Regul Integr Comp Physiol. 2005;288(2):R345-53.

11. Garber CE, Blissmer B, Deschenes MR, Franklin BA, Lamonte MJ, Lee IM, et al. American College of Sports Medicine position stand. Quantity and quality of exercise for developing and maintaining cardiorespiratory, musculoskeletal, and neuromotor fitness in apparently healthy adults: guidance for prescribing exercise. Med Sci Sports Exerc. 2011:43(7):1334-59.

12. Tibana RA, Pereira GB, Navalta JW, Bottaro M, Prestes J. Acute effects of resistance exercise on 24-h blood pressure in middle aged overweight and obese women. Int J Sports Med. 2013;34(5):460-4.

13. Williams MA, Haskell WL, Ades PA, Amsterdam EA, Bittner V, Franklin BA, et al. Resistance exercise in individuals with and without cardiovascular disease: 2007 update: a scientific statement from the American Heart Association Council on Clinical Cardiology and Council on Nutrition, Physical Activity, and Metabolism. Circulation. 2007;116(5):572-84.

14. Petersen AM, Pedersen BK. The anti-inflammatory effect of exercise. J Appl Physiol (1985). 2005;98(4):1154-62
15. Kim HS, Kim DG. Effect of long-term resistance exercise on body composition, blood lipid factors, and vascular compliance in the hypertensive elderly men. J Exerc Rehabil. 2013;9(2):271-7

16. Jakicic JM, Clark K, Coleman E, Donnelly JE, Foreyt J, Melanson E, et al. Appropriate intervention strategies for weight loss and prevention of weight regain for adults. Med Sci Sports Exerc 2001;33(12):2145-56.

17. Donnelly JE, Blair SN, Jakicic JM, Manore MM, Rankin JW, Smith BK, et al. Appropriate physical activity intervention strategies for weight loss and prevention of weight regain for adults. Med Sci Sports Exerc. 2009;41(2):459-71.

18. Santos MG. Pegoraro M, Sandrini F, Macuco EC. Fatores de risco no desenvolvimento da aterosclerose na infância e adolescência. Arq Bras Cardiol. 2008;90(4):301-8.

19. Ogawa K, Sanada K, Machida S, Okutsu M, Suzuki K. Resistance exercise training-induced muscle hypertrophy was associated with reduction of inflammatory markers in elderly women. Mediators Inflamm. 2010:2010:171023.

20. Silveira LR, Pinheiro CH, Zoppi CC, Hirabara SM, Vitzel KF, Bassit RA, et al. Regulation of glucose and fatty acid metabolism in skeletal muscle during contraction. Arq Bras Endocrinol Metabol. 2011;55(5):303-13.

21. Brito CJ, Volp ACP, Nóbrega OT, Júnior FLS, Mendes EL, Roas AFC, et al. Exercício físico como fator de prevenção aos processos inflamatórios decorrentes do envelhecimento. Motriz. 2011;17:544-55.

22. Ho SS, Dhaliwal SS, Hills AP, Pal S. Effects of chronic exercise training on inflammatory markers in Australian overweight and obese individuals in a randomized controlled trial. Inflammation. 2013;36(3):625-32.

23. Lee JS, Kim CG, Seo TB, Kim HG, Yoon SJ. Effects of 8-week combined training on body composition, isokinetic strength, and cardiovascular disease risk factors in older women. Aging Clin Exp Res. 2015;27(2):179-86.

24. Prestes J, Foschini D, Marchetti P, Charro MA. Prescrição e Periodização do Treinamento de Força em Academias. Barueri, SP: Manole; 2010

25. Mavros Y, Kay S, Simpson KA, Baker MK, Wang Y, Zhao RR, et al. Reductions in C-reactive protein in olde adults with type 2 diabetes are related to improvements in body composition following a randomized controlled trial of resistance training. J Cachexia Sarcopenia Muscle. 2014;5(2):111-20.

26. Lera Orsatti F, Nahas EA, Maestá N, Nahas Neto J, Lera Orsatti C, Vannucchi Portari G, et al. Effects of resistance training frequency on body composition and metabolics and inflammatory markers in overweight postmenopausal women. J Sports Med Phys Fitness. 2014;54(3):317-25. 